\title{
OBITUARY
}

\section{Peter Knight McCowan}

Peter Knight McCowan, President of the Royal Medico-Psychological Association in 1951, and an Honorary Fellow of our College, died on 17 March at the age of 88.

Dr McCowan, an Edinburgh graduate of 1912, entered our specialty after experience in general practice and in the RAMC of the Great War. His psychiatric career was threefold: in the LCC service, that nursery of so many distinguished men; in Cardiff, as Physician Superintendent of the City Mental Hospital at Whitchurch and Lecturer in the Welsh National School of Medicine; and finally in his two decades as Physician Superintendent of Crichton Royal, where his clinical foresight and administrative genius came to a remarkable fruition.

His academic distinctions are obvious from his qualifications, -M.D., F.R.C.P. and Barrister at Law; here one may rather enlarge on his contribution to the R.M.P.A., of which he was Bronze Medallist in 1926. In 1931 he became Secretary of the Research and Clinical Committee (and later of that Section) a post he was to hold for twenty years. These are now distant days, but it was from this Committee, before and immediately after the Second War, that our many Sections were evolved. A relatively small group of psychiatrists thus initiated a remarkable expansion in the educational and scientific activities of the Association, thereby laying one of the foundations for Collegiate status.

Dr McCowan's personal contribution was further acknowledged by his acting as Chairman of the Papers and Discussions Committee (1946-49) and by serving as Co-Editor of the Joumal from 1945 to 1957. His Chairmanship of the Scottish Division preceded his Presidency in 1951.

His achievement within the Association was paralleled by a highly creative professional life in Dumfries. His arrival at Crichton Royal, that large and wealthy endowment, coincided with the beginning of the therapeutic revolution in psychiatry, and $\mathrm{Dr}$ McCowan's remarkable and indeed almost ruthless drive soon placed his hospital in the vanguard of this progress. No doubt all men have anxieties and uncertainties, but his were not worn on the sleeve; and a blunt and deceptively simplistic approach to any problem concealed a very subtle summation of possibilities. He was greatly supported by a highly informed Board of Directors, and the takeover by the NHS in 1948 only brought out in him and them a robust but skilful disregard of any unsound suggestions from higher authority. An admirable aspect of his character was his intense desire to recruit and welcome colleagues of equal though different distinction. Among those already, or to become, eminent, may be mentioned Mayer-Gross, Raven, Stengel and Roth, although in truth this list could be multiplied several times. He had the capacity to sustain and hold the respect of colleagues in many disciplines whose temperaments and preoccupations were radically different from his own. Under his leadership the hospital thrived not only in research, training and medically-orientated treatment, but in pioneering the expansion of social work, clinical psychology, advanced nursing and milieu therapies; for his remarkably wide vision identified, early, each growing point in psychiatric practice.

After retirement, and in his penultimate years, his mind did not lose its directness of perception. It was the duty and pleasure of his younger colleagues to drive him to meetings, and thereafter to enjoy, over a glass of good whisky, his sometimes tart comments, well flavoured with illuminating professional indiscretions; for he was fundamentally a humorous and sociable man.

His epitaph is twofold. He contributed greatly to the development of the Association, and thus to the groundwork for the College. For the rest, the autocracy, or meritocracy, of the old Physician Superintendent system is long out-moded; but when it worked, as it did for him, it worked to the great benefit of patients.

A. C. TAIT 